This item was submitted to Loughborough's Research Repository by the author.

Items in Figshare are protected by copyright, with all rights reserved, unless otherwise indicated.

\title{
Reflection-impulsivity in athletes: a cross-sectional and longitudinal investigation
}

\section{PLEASE CITE THE PUBLISHED VERSION}

https://doi.org/10.1080/17461391.2020.1861106

\section{PUBLISHER}

Taylor \& Francis

\section{VERSION}

AM (Accepted Manuscript)

\section{PUBLISHER STATEMENT}

This is an Accepted Manuscript of an article published by Taylor \& Francis in European Journal of Sport Science on 11 Jan 2021, available online: http://www.tandfonline.com/10.1080/17461391.2020.1861106.

\section{LICENCE}

CC BY-NC-ND 4.0

\section{REPOSITORY RECORD}

Vaughan, Robert S, Jack D Hagyard, Elizabeth J Edwards, and Robin Jackson. 2021. "Reflection-impulsivity in Athletes: A Cross-sectional and Longitudinal Investigation”. Loughborough University. https://hdl.handle.net/2134/13343324.v1. 


\section{European Journal of Sport Science}

European Journal of Sport Science

R Routledge

\section{Reflection-impulsivity in athletes: A cross-sectional and longitudinal investigation}

Robert S. Vaughan, Jack D. Hagyard, Elizabeth J. Edwards \& Robin C. Jackson

To cite this article: Robert S. Vaughan, Jack D. Hagyard, Elizabeth J. Edwards \& Robin C. Jackson (2020): Reflection-impulsivity in athletes: A cross-sectional and longitudinal investigation, European Journal of Sport Science

To link to this article: https://doi.org/10.1080/17461391.2020.1861106

Accepted author version posted online: 07

Dec 2020.

Submit your article to this journal $₫$

Q View related articles ¿

View Crossmark data $[\pi$ 
Publisher: Taylor \& Francis \& European College of Sport Science

Journal: European Journal of Sport Science

DOI: $10.1080 / 17461391.2020 .1861106$

Check for updates

\title{
Reflection-impulsivity in athletes: A cross-sectional and longitudinal investigation
}

\author{
Robert S. Vaughan \& Jack D. Hagyard \\ York St John University, UK \\ Elizabeth J. Edwards
}

The University of Queensland, Australia

$\&$

Robin C. Jackson

Loughborough University, UK

Author Note

Correspondence concerning this article should be addressed to Robert Vaughan, School of Education, Language, and Psychology, York St John University, Lord Mayors Walk, York, UK, YO317EX, E-mail: r.vaughan@yorksj.ac.uk

\begin{abstract}
Reflection-impulsivity is a dimension of cognitive or decision-making style. We conducted two quasi-experimental studies to examine reflection-impulsivity in athletes using an information sampling task. In Study $1\left(n=108 ; M_{\text {age }}=22.7 \pm S D_{\text {age }}=1.42 ; 50 \%\right.$ female $)$, we used a crosssectional design to compare performance across athletic expertise (super-elite, elite, amateur, novice or non-athlete) and sport type (external-paced or self-paced). In Study 2 (Time $1 n=106$; $M_{\text {age }}=21.21 \pm S D_{\text {age }}=3.87 ; 53 \%$ female and Time $2 n=64 ; M_{\text {age }}=21.18 \pm S D_{\text {age }}=3.95 ; 44 \%$ female), we examined changes in reflection-impulsivity across a 16-week playing season. Study 1 showed more accurate and more efficient performance as athletic expertise increased. Study 2 revealed better effectiveness and efficiency following sport participation, a 16-week playing
\end{abstract}


season, most notably in elite-level performers. No sport-type differences were noted. Taken together, the studies demonstrate an association between reflection-impulsivity and athletic expertise, while also providing evidence that competitive sports participation leads to efficient decisions based on reflection, without sacrificing accuracy, which is often a consequence of impulsive decision-making.

Key Words: Reflection-Impulsivity, Decision-Making, Athlete Expertise

\section{Introduction}

Competitive sport environments are laden with situations that require athletes to receive, process, and respond to external stimuli (Williams, Anshel, \& Quek, 1997; Williams \& Jackson, 2019). Much of the research on individual differences in these abilities has focused on the role of cognitive styles and researchers have used a variety of methodological contexts. For example, elite level athletes have been shown to use a combination of cognitive and affective styles to anticipate and respond to changing situations (e.g., Verburgh, Scherder, van Lange, Oosterlaan, 2014), avoid distractions and resolve interference in play (e.g., Furley \& Wood, 2016), and make more effective decisions (e.g., Vaughan, Laborde, \& McConville, 2019). However, the link between individual differences in cognition and sports performance remains poorly understood and continuing research is required to elucidate this complex association.

\section{Reflection-Impulsivity in Sport}

Many sports require players to use complex cognitive processes on a second-to-second basis (Walsh, 2014), that is, successful play requires a continuous stream of executive processes (e.g., inhibition, shifting, updating, reflective and impulsive decision-making; Voss, Kramer, Basak, Prakash, \& Roberts, 2010). For example, in a game of soccer a sequence of open play requires players to inhibit inappropriate actions or impulsive decisions (e.g., ignoring players calling for the ball who may not be clear from opposition), shift cognitive resources between 
different information sources for potential pass options (e.g., keeping the ball or passing to a team mate), and update available information to discard ineffective plans (e.g., monitoring play based on proximity and readiness to kick at goal). We reason that the ability to process information with regard to risk and reward may be particularly important for decision-making in sport situations. In accord with Williams et al. (1997), we argue that athletes may be more successful at optimising the balance between risk and reward in sporting environments with intrinsic information overload. As such, we suggest that athletes might be more efficient at assessing the situation and making correct choices with good speed, than non-athletes. This notion, however, remains to be tested.

Researchers have identified three subtypes of behavioural impulsivity (Evenden, 1999): motor-impulsivity (or inhibitory control) refers to the inability to withhold a dominant response; temporal-impulsivity refers to the inability to delay gratification; and reflection-impulsivity refers to the degree to which an individual reflects on the validity of choices (reflection) or makes decisions in times of uncertainty (impulsivity; see Kagan, 1966). To date, there are no studies on reflection-impulsivity in athletes and no behavioural tests of reflection-impulsivity in the context of sport. Indicative findings come from studies of executive processes, some of which have shown that athletes outperform non-athletes on tests of inhibitory control (e.g., Brevers et al., 2018; Wang et al., 2013) and decision-making (e.g., Vaughan et al., 2019), and that processing efficiency is impaired on an anticipation test under heightened anxiety (Cocks, Jackson, Bishop, \& Williams, 2016). Others have reported no differences between athletes and non-athletes on measures of inhibition (e.g., Chang et al., 2017) and decision-making (e.g., Jacobson \& Matthaeus, 2014).

Research on inhibition in sport is particularly relevant given its conceptual association with impulsivity. Brevers et al. (2018) found that elite fencers and taekwondo competitors had faster reaction times (RT) on a stop signal task, relative to non-athletes. Similar findings were 
reported by Wang et al. (2013) with tennis players compared to non-athletes. Martin et al. (2016) found that professional cyclists had faster RTs on a Stroop task, than recreational cyclists. Chang et al. (2017), however, found no differences in RTs between endurance athletes, martial arts athletes and non-athletes on their Stroop task. One reason for the conflicting results between studies could be that there are inherent problems with interpreting performance efficiency (e.g., RT) data without consideration of speed-accuracy trade-offs. Specifically, the use of RT alone is only appropriate if all individuals perform with equal accuracy. Given individual differences in performance, a more sensitive measure of efficiency would be best indexed as a ratio of accuracy to RT (cf. Edwards, Moore, Champion \& Edwards, 2015). Another explanation for conflicting results between studies might be due to individual differences such as sport type (Singer, 2000).

Jacobson and Matthaeus (2014) suggested that inhibition differed by sport type and compared the performance of athletes from self-paced (e.g., swimming, running) and externallypaced sports (e.g., soccer, basketball; see Singer, 2000) on tests of inhibitory control and decision-making. They found athletes outperformed non-athletes on a modified Stroop (inhibition), but not on a modified Tower of London (decision-making) task. Importantly, selfpaced athletes outperformed externally-paced athletes on inhibitory control, yet externally-paced athletes scored higher on decision-making. It is possible that the relationship differs for simple executive functions (inhibition), rather than complex executive functioning (decision-making). Alternatively, following the notion that cognitive competence predicts athletic success (Vestberg et al., 2017), and the idea that people enjoy doing what they do well, Jacobson and Matthaeus (2014) concluded that it is probable that individuals with high cognitive abilities might be drawn to sports because they have good executive functioning, and their skills develop further with training in a reinforcing cycle. It is plausible therefore, that self-paced sports may favour 
athletes who are more reflective and focus on their decisions, whereas externally-paced sports favour athletes who perform with both reflection and speed (efficiency).

The cause and effect relationship between cognition and athletic performance or vice versa is an enduring question (Voss et al., 2010) and signals the need for designs that can inform causality (e.g., longitudinal). Whilst more work is needed, empirical evidence alludes to the existence of a causal relationship. For example, Hagyard, Brimmell, Edwards, and Yaughan (2020) reported that those with more athletic expertise scored higher than those with less expertise on a stop signal task of inhibitory control and this effect remained over a 16 -week period. They also reported that across a playing season, stop signal task performance predicted athlete- and coach-ratings of performance and this relationship was moderated by athletic expertise, such that those with more expertise demonstrated better inhibition and sporting performance. These reported effects were independent of moderate to vigorous physical activity (MVPA). Similar findings were reported by Vestberg et al. (2012) who found that better inhibition was related to better performance over two seasons in elite and sub-elite soccer players. Moreover, longitudinal work with children has reported increased working memory performance in 6-11 year olds participating in a tennis play intervention (Ishihara \& Mizuno, 2018) and meta-analytic reviews of the relationship between executive function and physical activity support the causal direction that sport performance enhances cognitive performance (de Greef et al., 2018; Verbugh et al., 2014). Despite the problems associated with individual differences in executive functions across the developmental pathway in children (see Crone \& Dahl, 2012, for review), taken together this research suggests that it is likely that athletic expertise and executive functions may reciprocally develop in tandem.

\section{Assessment of Reflection-Impulsivity}

The matching familiar figures task (MFF20; Cairns \& Cammock, 1978) was designed to index reflection-impulsivity. In the MFF20 participants select one of six visual stimuli to match 
an original image. The test captures a total impulsivity score based on the standardised mean RT minus the standardised total errors. Positive scores correspond to reflective processing (fewer errors, but slow, deliberate performance) and negative scores indicate impulsive processing (more errors, yet faster responses). The MMF20 has been used extensively to index reflectionimpulsivity in clinical populations (e.g., Morgan, Impallomeni, Pirona, \& Rogers, 2006), however, few studies have used the MFF20 with healthy adults. As such, the reliability and validity of the MFF20 to capture reflection-impulsivity in a healthy sample is unknown. Further, the MFF20 has been criticised for being confounded by other cognitive processes such as visual processing and working-memory (see Clark, Robbins, Ersche, \& Sahakian, 2006).

The information sampling task (IST; Clark et al., 2006) was designed to be a relatively process-pure measure of reflection-impulsivity. The IST has been used to measure reflectionimpulsivity in studies with healthy adults (e.g., Crockett, Clark, Smillie \& Robbins, 2012) and clinical samples (e.g., Irvine et al. 2013). In the IST, participants are presented with an array of grey boxes from which they select one box at a time to reveal one of two colours. The information revealed with each box choice is used to decide which of the colours is in the majority behind the grey boxes. The IST produces three outcome measures: IST Correct is the average number of boxes opened for each trial (i.e., in order to inform a decision); IST Errors is the number of incorrect decisions across trials; and IST Latency is the RT (in milliseconds; ms) of decision responses across trials. Individuals who gather information systematically and have higher IST Correct scores display tendencies for reflection. Whereas, individuals who make decisions with less information, consequently make more errors (IST Errors) and show impulsive tendencies. Bennett and colleagues (2017), suggested that the IST Correct calculation assumes equal probability that unopened box colours are unrelated to the boxes already opened, yet in effect, the colours of the opened boxes provide vital information about the box colours still to be revealed. Given the potential for IST Correct to overestimate effectiveness (accuracy) 
of reflection-impulsivity performance, we argue for application of signal detection theory (Stanislaw \& Todorov, 1999) to provide a sensitivity score that incorporates the number of correct box choices and errors (cf. Edwards, Edwards \& Lyvers, 2017).

\section{The Current Study}

In the present study we measured reflection-impulsivity using a computerised IST. We operationalised effectiveness (accuracy) using the sensitivity index $\left(d^{\prime}\right)$ from signal detection theory (Stanislaw \& Todorov, 1999), and efficiency as the ratio of accuracy to RT. We predicted that performance would differ across athletic expertise (super-elite, elite, amateur, novice and non-athletes; see Swann, Moran \& Piggott, 2015) such that athletes with greater expertise would perform with better effectiveness and efficiency than their lesser expert counterparts. We also predicted that performance would vary across sport-type (externally-paced, self-paced, nonathlete; see Singer, 2000), such that, externally-paced athletes would be more efficient than selfpaced athletes, or non-athletes. Given research that has showed that MVPA enhances sportspecific cognitive performance (Chan et al., 2011; Williams \& Ericsson, 2005), we controlled for MVPA in our data analyses. Our investigation comprised two studies.

\section{Study 1}

To test the hypotheses regarding differences across athlete expertise and sport type in reflection-impulsivity we employed a cross-sectional design. We predicted that after controlling for MVPA, athletes with higher expertise would demonstrate better reflection-impulsivity performance effectiveness and efficiency, compared to athletes with less expertise. Second, we hypothesised that externally-paced athletes would perform more efficiently than self-paced athletes.

\section{Methods}

\section{Participants}


One hundred and eight volunteers aged 18 to 28 years, with a mean playing experience of 9.74 years, participated $\left(M_{\text {age }}=22.7 \pm S D_{\text {age }}=1.42 ; 50 \%\right.$ female $)$. Classification of athletic expertise followed Swann et al.'s (2016) recommendation (i.e., non-athlete $=24$, novice $=29$, amateur $=25$, elite $=17$ and super-elite $=13)$. Categorisation of externally-paced $(n=62)$ and self-paced $(n=44)$ sports followed Singer (2000). Participants were recruited from the university sport and psychology departments and volunteers were remunerated with research participation credit points. G*Power sample size calculator for ANCOVA suggested a sample size of 80 and 196 to detect large effects $(f=0.4)$ and medium effects $(f=0.25)$, respectively $(1$ $-\beta=.80, \alpha=.05 ;$ Faul, Erdfelder, Lang, \& Buchner, 2007), with a sample size of 108 yielding sensitivity of $\mathrm{f}=0.34$.

\section{Materials}

International Physical Activity Questionnaire (IPAQ; Booth, 2000). The 9-item (short form) of the IPAQ was used to index health-related physical activity in the last seven days (i.e., MVPA). Items focus on the frequency and duration of vigorous and moderate-intensity activities and indicators of sedentary behaviour (i.e., sitting and walking) e.g., During the last 7 days, on how many days did you do moderate physical activities like carrying light loads, bicycling at a regular pace, hiking? Do not include walking. We used the moderate and vigorous subscales, such that total scores were calculated as minutes $\mathrm{x}$ days spent engaging in physical activity. Higher scores represented greater MVPA. Research suggests the IPAQ is a reliable and valid measure for participants aged 18-59 years old (Nigg et al., 2020).

Information Sampling Task (IST). The information sampling task from the Cambridge Automated Neuropsychological Test Battery (CANTAB; Clark et al., 2006) was used to measure reflection-impulsivity. Participants were presented with a 5 x 5 grid of grey boxes on a screen and instructed that they are playing for points. They select grey boxes one at a time to reveal one of two colours. Once a box has been selected, it remains open for the duration of the 
trial. Participants are asked to decide which colour box is in the majority, by indicating their choice on a panel at the bottom of the screen. Points are awarded for correctly deciding which colour is in the majority. IST Correct, IST Errors, and IST Latency (RT in ms) is captured. The task began with a single practice trial, followed by 20 test trials.

\section{Reflection-Impulsivity Performance}

Effectiveness. We followed other work that has calculated effectiveness or accuracy on executive tasks using d' (e.g., Edwards et al., 2017). The following equation was used:

$$
\text { Effectiveness } d^{\prime}=z \text { IST Correct }-z \text { IST Errors }
$$

Efficiency. Efficiency was operationalised as Effectiveness $\left(d^{\prime}\right)$ divided by the Mean IST Latency (ms). To aid interpretation we multiplied the ratio by 1000 (see Edwards et al., 2017) in the following equation:

$$
\text { Efficiency }=\frac{d^{\prime}}{\text { Mean IST Latency ms }} \times 1000
$$

\section{Procedure}

The study was approved by the University's ethics committee and signed informed consent was collected prior to participation. Participants were tested individually in quiet, designated laboratories and testing was completed on a GIGABYTE 7260HMW BN touchscreen computer running a Pro Windows 8 operating system with a high resolution 12-inch display. To begin, participants were briefed on the study protocol and ethical issues pertaining to withdrawal and confidentiality and provided the opportunity to ask questions. Next, participants provided demographic information (e.g., age, sex, and sport participation details), and then completed the IPAQ followed by the IST. Finally, participants were debriefed, thanked and released. Testing took approximately 20 minutes. Data were entered onto SPSSv24 for analysis.

\section{Design and Data Analysis}

A two-way cross-sectional design was used. To isolate differences in MVPA across athlete expertise, a one-way between subjects MANOVA model was constructed. Scores on 
vigorous, moderate, and walking subscales of the IPAQ were entered as dependent variables and athletic expertise as the independent variable. To test for differences in reflection-impulsivity across athletic expertise and sport type, separate two-way ANCOVAs were conducted for performance effectiveness and performance efficiency, with total MVPA entered as the covariate. Significant effects were followed up with Bonferroni-corrected pairwise comparisons.

\section{Results}

\section{Descriptive Statistics and Baseline Modelling}

Measures of central tendency were tabulated for reflection-impulsivity across expertise and sport type (see Table 1). MANOVA modelling indicated a significant multivariate difference between athletes of varying expertise on MVPA, Wilks' $\lambda=.77, \mathrm{~F}(15,276.39)=$ $8.61, p=.001 ; \eta \rho^{2}=.18$. There was a significant group difference on the measure of vigorous (F $\left.(5,102)=5.67, p=.001, \eta \rho^{2}=.19\right) ;$ moderate $\left(\mathrm{F}(5,102)=5.18, p=.001, \eta \rho^{2}=.17\right) ;$ and walking activity $\left(\mathrm{F}(5,102)=4.10, p=.003, \eta \rho^{2}=.14\right)$. Results indicated that higher levels of athletic expertise scored significantly higher on all measures of MVPA, supporting the use of MVPA as a covariate in subsequent analyses.

\section{Reflection-Impulsivity and Expertise}

Results of ANCOVA revealed a significant difference in reflection-impulsivity effectiveness $(F(4,102)=5.88, p<.01)$ and efficiency $(F(4,102)=1.87, p<.01)$ by athletic expertise, with higher scores across higher levels of expertise. More specifically, athletes were able to focus and make correct decisions (reflection) and do so without an efficiency cost (that would indicate an impulsive style). Post-hoc analyses indicated significantly higher scores in elite and super-elite athletes compared to their non-elite counterparts with no difference between novice and amateurs. Regarding sport type, no differences were noted for effectiveness or efficiency between externally-paced, self-paced athletes and non-athlete controls. 


\section{Discussion}

In Study 1 we examined differences in reflection-impulsivity performance (effectiveness \& efficiency) across athletic expertise. Consistent with our hypothesis, higher-level athletes were more effective and more efficient than their lower-level counterparts. There is no existing data examining reflection-impulsivity in athletes, however, we agreed with previous research indicating positive associations between athletic expertise, and inhibition (Brevers et al., 2018), and decision-making (Vaughan et al., 2019). Our findings extend the current understanding of the relationship between cognitive performance and athlete expertise by demonstrating that those with more expertise make more deliberate decisions (based on reflection) without sacrificing the time taken to respond. Our pattern of results, however contrasts work that reported no association between athlete expertise and inhibition (Chang et al., 2017) or decisionmaking (Jacobson \& Matthaeus, 2014). Given that the current study is the first to provide a direct test of reflection-impulsivity in sport, we suggest the most plausible explanation for differences between our results and that of Chang et al., (2017) and Jacobson and Matthaeus (2014) rests with task differences (i.e., Chang et al. used a Stroop task to assess inhibition; and Jacobson \& Matthaeus used a Toyer Test to index decision-making). We propose that despite being conceptually similar, reflection-impulsivity, and accordingly performance on the IST, requires distinctly different processes than those involved with performance of the Stroop (inhibition) and Tower Test (decision-making).

Study 1 was the first study to examine the association between sport-type and reflectionimpulsivity. Our results revealed that sport-type was not associated with the effectiveness or efficiency of reflection-impulsivity performance. The present results contrast work that reported self-paced athletes have superior inhibition than externally-paced and externally-paced athletes are better decision-makers than self-paced athletes (Jacobson \& Matthaeus, 2014). The reason for differences between our study and Jacobson and Matthaeus (2014) is puzzling. If sport-type 
was linked to performance on complex executive tasks (i.e., decision-making, reflectionimpulsivity) we would have expected to find externally-paced athletes performing better than self-paced athletes on the IST, but this was not the case. The most reasonable explanation therefore, rest with methodological differences between studies, that is, our novel use of the sensitivity parameter and our analyses controlling for MVPA.

The cross-sectional design used in Study 1 was unable to determine whether group differences were due to participation in the sport or whether higher scores conferred a development and selection advantage. Few studies have investigated the effect of sport participation on executive function, longitudinally. For example, Vestberg et al. (2012) found that inhibition was positively associated with the number of goals and assists over two seasons in elite and sub-elite soccer players. Likewise, Hagyard et al. (2020) reported better inhibition via stop signal task performance over a 16-week period and this effect also predicted sport performance over a playing season. In other work, Spindler et al. (2017) found that athletes demonstrated better decision-making performance following 20 minutes of sustained aerobic activity, relative to baseline. Similar findings were reported by Ishihara and Mizuno (2018) who showed that playing four sessions of tennis per week was associated with greater improvements in working-memory over a 12-month period than did playing one session per week, irrespective of MVPA. The aim of Study 2, therefore, was to test whether reflection-impulsivity performance (effectiveness \& efficiency) improves with sport participation.

\section{Study 2}

To assess changes in reflection-impulsivity performance effectiveness and efficiency following sport participation, we used a longitudinal design. We measured performance on the IST from Study 1, and captured effectiveness and efficiency before (Time 1) and after (Time 2), a 16-week playing season. We hypothesised that greater athletic expertise would be related to better reflection-impulsivity effectiveness and efficiency at Time 1 (in accord with Study 1), and 
would improve from Time 1 to Time 2. For continuity and to test the robustness and generalisability of our findings, we retained our hypothesis that externally-paced athletes would demonstrate greater efficiency than self-paced athletes, and that these effects would be independent of MVPA. G*Power analysis for the within-between interaction (repeated measures ANOVA, $f=0.25,1-\beta=.80, \alpha=.05)$ yielded a suggested sample size of 55 and 34 for the Time $\mathrm{x}$ Expertise and Time $\mathrm{x}$ Sport type interactions, respectively. To allow for attrition we recruited 106 participants for the study.

\section{Methods}

\section{Participants}

Table 3 shows the demographic characteristics of participants at Time $1\left(n=106 ; M_{\text {age }}=\right.$ $21.21 \pm S D_{\text {age }}=3.87 ; 53 \%$ female $)$ and Time $2\left(n=64 ; M_{\text {age }}=21.18 \pm S D_{\text {age }}=3.95 ; 44 \%\right.$ female), representing 39.7\% attrition rate. Recruitment and ethical protocols followed Study 1 , however, no participants completed both studies.

\section{Materials}

The materials were the same as those used in Study 1.

\section{Reflection-impulsivity Performance}

The same measures of IST effectiveness and efficiency were used.

\section{Procedure}

The same procedures in Study 1 were used, with the inclusion of a 16-week follow up. Testing procedures at Time 2 (end of season) followed the same as Time 1 (start of season).

\section{Design and Data Analytic Technique}

A two-way quasi-experimental design was used with a 16-week longitudinal follow-up (Ardoy et al., 2014). Treatment of MVPA as a covariate was again analysed following Study 1 (e.g., one-way between subjects MANOVA). To assess the cross-sectional differences in reflection-impulsivity across athletic expertise, after controlling for MVPA, separate ANCOVA 
models were constructed to replicate study 1 . Effectiveness and efficiency were used as dependent variables, athlete expertise and sport type were entered as independent variables, and MVPA as the covariate.

Longitudinal effects were tested with regression-based modelling (Ishihara \& Mizuno; 2018). Given that data was collected at two time points, inter-class-correlations were used to determine test-retest reliability (Tabachnick \& Fidell, 2007). All variables indicated acceptable levels of stability $(\alpha=.78-.89)$. The data were screened for multivariate outliers via Mahalanobis distance which revealed no outliers $>3$ degrees of freedom $\left(x^{2}(10)=5.97, p<.01\right.$; Tabachnick \& Fidell, 2007). Linear regression modelling assumes that all observations in the data are independent of each other, which is violated in longitudinal data. Linear mixed models (LMM) relax this assumption and allow for observations on the dependent variable to have nonzero covariance and enable researchers to examine residual changes over time. Two LMM's observing changes in effectiveness and efficiency (controlling for MVPA) across athletic expertise were constructed (cf. West, 2009). There were two sources of variation; over time and between athletes, thus, an unconditional model with no fixed effects provided an estimate of variance at both levels. Subsequent fixed models with changes in impulsive decision-making between Time 1 and Time 2 were added as predictor variables. The restricted maximum likelihood estimation method was used to provide unbiased estimates of the variance (West, 2009).

\section{Results}

\section{Descriptive Statistics and Baseline Modelling}

Measures of central tendency were tabulated for effectiveness and efficiency across expertise and sport type at time 1 and time 2 (see Table 1). MANOVA modelling indicated a significant multivariate difference between the athletes of varying expertise on MVPA, Wilks' $\lambda$ $=.63, F(12,256.93)=4.15, p=.001 ; \eta \rho^{2}=.15$. There was a significant group difference on the 
measure of vigorous $\left(F(4,99)=4.90, p=.001, \eta \rho^{2}=.17\right)$; moderate $(F(4,99)=4.59, p=.001$, $\left.\eta \rho^{2}=.16\right)$; and walking activity $\left(F(4,99)-3.37, p=.005, \eta \rho^{2}=.12\right)$. Results indicated that more expert athletes scored significantly higher on all measures of MVPA, therefore MVPA was again entered as a covariate in subsequent analyses. To check for speed-accuracy confounds in the data, we examined the relationship between IST Errors and IST Latency. The bivariate correlation indicated that more errors were associated with longer latencies $(r(62)=-.27, p=$ $.01)$ thus eliminating the possibility of a speed-accuracy trade-off.

\section{ANCOVA Modelling}

Differences in reflection-impulsivity were analysed across sport type and expertise entering MVPA as a covariate (see Table 2). Results indicated a significant variation on effectiveness and efficiency by athletic expertise, with higher expertise predominantly outperforming those of lesser expertise. Post-hoc analyses indicated significantly greater performance in elite and super-elite athletes compared to their non-elite counterparts. No significant differences were found with sport-type.

\section{Linear Mixed Models}

An initial unconstrained model over Time 1 and Time 2 revealed significant individual variance in slopes and intercepts of reflection-impulsivity $(p<.01)$ indicating that participants varied in their performance at Time 1 . Next, two main effect models examining reflectionimpulsivity changes over the 16-week period across athletic expertise controlling for MVPA were tested (see Table 4). In both instances residual changes in the variance were significant i.e., effectiveness $(\beta=1.98, S E=.04,95 \%$ CI [1.35 - 2.34]; see Figure 1$)$ and efficiency $(\beta=1.18$, $S E=.03,95 \%$ CI [.92 - 1.80]; see Figure 2). In general, growth trajectories were significantly different across expertise $(p<.01)$, and typically larger in those with more expertise compared to those with less expertise. Therefore, participants competing at higher levels observed greater 
increases in their ability to make accurate and efficient deliberate decisions from Time 1 to Time 2 independent of their MVPA levels.

\section{Discussion}

Study 2 was an extension of Study 1. Cross-sectional findings at Time 1 concurred with Study 1 . Athletes with higher athletic expertise demonstrated better reflection-impulsivity effectiveness and efficiency than those with less expertise, independent of MVPA and no differences were found between externally- and self-paced athletes. Considering longitudinal findings, as predicted, athletes demonstrated greater increases in ability to make efficient decisions (without sacrificing accuracy) compared to non-athletes. The growth trajectories at 16weeks showed the largest increases in elite level athletes between Time 1 and Time 2. Our results concur with others who have found increases in executive function across time in sports contexts (e.g., Hagyard et al., 2020; Vestberg et al., 2012; 2017; Ishihara \& Mizuno, 2018), nonetheless there are no comparative reflection-impulsiyity data for these longitudinal findings.

\section{General Discussion}

We have reported two studies that have examined differences in reflection-impulsivity between athletes of varying expertise (i.e. super-elite, elite, amateur, novice, \& non-athletes) and sport-type (i.e. external- \& self-paced athletes), whilst controlling for MVPA. In Study 2, change in performance across a 16-week playing season was also tested. Akin to research outside of sport, reflection-impulsivity is an important cognitive process across individual differences (Irvine et al., 2013; Morgan et al., 2006). That is, the ability to better evaluate information before making a decision is linked with greater athletic expertise (Williams et al., 1997).

Results from Study 1 corresponded with Study 2 (Time 1). In the absence of existing work examining refection-impulsivity in sport, we highlight that our findings concurred with studies reporting better inhibitory control and decision-making in elite athletes relative to non- 
athletes (Brevers et al., 2018; Spindler et al., 2017; Vaughan et al., 2019). Study 2 is the first to examine reflection-impulsivity across a playing season and provides support for the assumption that differences are likely attributable to increased sports participation in a competitive environment. For example, it is plausible that competitive sports environments provide greater opportunity to elicit goal-oriented behaviour, whilst under distractions which are dependent upon efficient decision-making (Williams \& Ericsson, 2005). It is possible, however, that the increased effect observed in elite athletes may be a practice effect from participation in highquality and cognitively demanding sports training (i.e., theory of expertise; Ericsson \& Smith, 1991) and the cognitive stimulation hypothesis (Tomporowski et al., 2008). This explanation nonetheless, is beyond the scope of the current work.

In Study 2, we demonstrated reflection-impulsivity improvements over a 16-week playing season. Noted improvements in elite-level athletes coincide with previous assertions that expertise is highly dependent on attentional resources (Williams et al., 2011). It is reasonable to suggest that performance in elite level sports requires participants to react, plan, and execute responses, under severe temporal constraint, in times that are shorter than actions (Walsh, 2014). It is plausible, therefore, that the ability to delay decision-making, consider alternatives and make deliberate choices, may be facilitative of athlete expertise, thus more successful performance. Whilst claims of causality between athletic expertise and executive functions are beyond the scope of the current work, we believe that the current data adds to evidence alluding to causality.For example, Crone and Dahl (2012) and de Greef et al. (2018) highlight that the development of executive functions are modified by participation in sports based activity in children and adolescents. These developmental trajectories may in part explain the positive relationship between executive function and later athlete performance (e.g., Hagyard et al., 2020; Ishihara \& Mizuno; 2018; Vestberg et al., 2012; 2017). 
Importantly, our findings remained significant after controlling for MVPA demonstrating that differences in reflection-impulsivity across athletic expertise are independent of physical activity. Whilst this finding has been observed in children and adolescents (Ishihara \& Mizuno; 2018) our findings are the first using an adult sample on a reflection impulsivity task. Like Hagyard et al. (2020) who reported better inhibition via stop signal task performance in those with more expertise independent of MVPA longitudinally, it is likely that the present results represent skill acquisition or learning effects from sport (De Luca et al., 2003), given that complex executive functions are instrumental to learning and may share a reciprocal relationship with sports participation i.e. the increase observed in the current research may be a result of coaching and learning new skills throughout the season (de Greef et al,, 2018).

Interestingly, the distinction between sport-type and reflection-impulsivity was not validated. That is, our findings did not agree with differences in sport-type reported by Jacobson and Matthaeus (2014). Despite some shared methodologies, there were also differences. Jacobson and Matthaeus (2014) examined inhibitory control and decision-making and we investigated reflection-impulsivity. As aforementioned, it is possible that sport-type is uniquely associated with particular executive functions and not others or by removing the variance related to MVPA we provided a more sensitive examination of the relationship between sport-type and reflection-impulsivity which is potentially inconsistent or reflective of other taxonomies relevant to executive functions such as static, interceptive and strategic sports (Krenn, Finkenzeller, Würth, \& Amesberger, 2018). It is understandable that athletes participating in team sports must determine the position of fellow players and opposing players and manipulate their actions to achieve their goal (Di Russo et al., 2010). By contrast, self-paced sports (e.g. swimming) place different demands on athlete's cognition. Therefore, another plausible account may rest with the assumption that the demands of playing in a team environment may induce situational pressures that have consequences for performance. For example, it has been shown that situational stress 
is linked to poorer inhibitory control (e.g., Edwards et al., 2017) and decision-making (e.g., Miu, Heilman, \& Houser, 2008) in non-athlete samples. However, no work has examined whether situational stress is linked to poorer reflection-impulsivity. Further work is needed to elucidate and untangle the combined relationship between situational stress, sport-type and reflectionimpulsivity in the sport context.

Despite numerous strengths, the current research is not without limitation. Collecting data at two time points enabled a within samples comparison of changes in reflectionimpulsivity from Time 1 (beginning of a playing season) to Time 2 (end of a 16-week playing season). Nonetheless, the study was not able to answer whether the improvements measured across the 16-week playing period, were sustainable. Future research warrants additional followup measures to determine whether reflection-impulsivity improvements are maintained over time. Despite the benefits of a longitudinal approach, our study did fall short of including assessment of training frequency and load, that is, details of sporting competition and training completed across the 16-week period (Brush et al., 2016). Extension of method could incorporate multiple time points over a longer period and further develop the longitudinal design to include interventions to assess the impact of specific training regimes on sport performance. New work may wish to combine sport-specific measures of reflection-impulsivity alongside general measures to augment the current findings. Researchers may also investigate the mediating effect of other variables (e.g., anxiety) on reflection-impulsivity under pressure in a sports context (Eysenck et al., 2007).

\section{Conclusion}

The present findings indicated a substantial association between athletic expertise and reflection-impulsivity, independent of MVPA. Our findings support the notion that long-term participation in competitive sport may facilitate reflection-impulsivity, making more efficient and deliberate decisions, which in turn may facilitate better sport performance (Hagyard et al., 
2020; Ishihara \& Mizuno, 2018). We propose that the reported improvements across the expertise continuum might implicate the trainability of reflection-impulsivity for the potential benefit of athletes. It is for future work to explore this.

\section{References}

Ardoy, D. N., Fernandez-Rodriguez, J. M., Jimenez-Pavon, D., Castillo, R., Ruiz, J. R., \& Ortega, F. B. (2014). A physical education trial improves adolescents' cognitive performance and academic achievement: The EDUFIT study. Scandinavian Journal of Medicine \& Science in Sports, 24(1), 52-61.

Bennett, D., Oldham, S., Dawson, A., Parkes, L., Murawski, C., \& Yücel, M. (2017). Systematic overestimation of reflection impulsivity in the Information Sampling Task. Biological Psychiatry, 82(4), e29-e30.

Booth, M. (2000). Assessment of physical activity: an international perspective. Research Quarterly for Exercise and Sport, 71, 114-120.

Brevers, D., Dubuisson, E., Dejonghe, F., Dutrieux, J., Petieau, M., Cheron, G., Verbanck., P., \& Foucart, J. (2018). Proactive and reactive motor inhibition in top athletes versus nonathletes. Perceptual and Motor Skills, 152(2), 289-312. doi: 0031512517751751.

Brush, C. J., Olson, R. L., Ehmann, P. J., Osovsky, S., \& Alderman, B. L. (2016). Doseresponse and time course effects of acute resistance exercise on executive function. Journal of Sport and Exercise Psychology, 38(4), 396-408.

Cairns, E., \& Cammock, T. (1978). Development of a more reliable version of the Matching Familiar Figures Test. Developmental Psychology, 14(5) (1978), 555-560

Chan, J. S. Y., Wong, A. C. N., Liu, Y., Yu, J., \& Yan, J. H. (2011). Fencing expertise and physical fitness enhance action inhibition. Psychology of Sport and Exercise, 12(5), 509514. 
Chang, E. C. H., Chu, C. H., Karageorghis, C. I., Wang, C. C., Tsai, J. H. C., Wang, Y. S., \& Chang, Y. K. (2017). Relationship between mode of sport training and general cognitive performance. Journal of Sport and Health Science, 6(1), 89-95.

Clark, L., Robbins, T. W., Ersche, K. D., \& Sahakian, B. J. (2006). Reflection-impulsivity in current and former substance users. Biological psychiatry, 60(5), 515-522.

Cocks, A. J., Jackson, R. C., Bishop, D. T., \& Williams, A. M. (2016). Anxiety, anticipation, and contextual information: An application of attentional control theory. Cognition and Emotion, 30, 1037-1048. DOI: 10.1080/02699931.2015.1044424.

Crockett, M. J., Clark, L., Smillie, L. D., \& Robbins, T. W. (2012). The effects of acute tryptophan depletion on costly information sampling: impulsivity or aversive processing? Psychopharmacology, 219(2), 587-597.

Crone, E. A., \& Dahl, R. E. (2012). Understanding adolescence as a period of social-affective engagement and goal flexibility. Nature Reviews Neuroscience, 13(9), 636-650.

de Greef, J. W., Bosker, R. J., Oosterlaan, J., Visscher, C., \& Hartman, E. (2018). Effects of physical activity on executive functions, attention and academic performance in preadolescent children: a meta-analysis. Journal of Science and Medicine in Sport, 21(5), 501-507.

De Luca, C. R., Wood, S. J., Anderson, V., Buchanan, J., Proffitt, T. M., Mahoney, K., \& Pantelis, C. (2003). Normative data from the Cantab. I: Development of executive function over the lifespan. Journal of Clinical and Clinical Neuropsychology, 25(2), $242-254$

Di Russo, F., Bultrini, A., Brunelli, S., Delussu, A. S., Polidori, L., Taddei, F., ... Spinelli, D. (2010). Benefits of sports participation for executive function in disabled athletes. Journal of Neurotrauma, 27(12), 2309-2319. 
Edwards, M. S., Moore, P., Champion, J. C., \& Edwards, E. J. (2015). Effects of trait anxiety and situational stress on attentional shifting are buffered by working memory capacity. Anxiety, Stress, and Coping, 28, 1-16.

Edwards, M. S., Edwards, E. J., \& Lyvers, M. (2017). Cognitive trait anxiety, stress and effort interact to predict inhibitory performance. Cognition \& Emotion, 31(4) 671-686.

Ericsson. K. A., \& Smith, J. (1991). Toward a general theory of expertise: Prospects and limits. Cambridge, England: Cambridge University Press.

Evenden, J. L. (1999). Varieties of impulsivity. Psychopharmacology, 146(4), 348-361.

Eysenck, M. W., Derakshan, N., Santos, R., \& Calvo, M. G. (2007). Anxiety and cognitive performance: attentional control theory. Emotion, 7, 336-353. doi.org/10.1037/15283542.7.2.336

Faul, F., Erdfelder, E., Lang, A. G., \& Buchner, A. (2007). G*Power 3: A flexible statistical power analysis program for the social, behavioral, and biomedical sciences. Behavior Research Methods, 39, 175-191.

Furley, P., \& Wood, G. (2016). Working memory, attentional control, and expertise in sports: A review of current literature and directions for future research. Journal of Applied Research in Memory and Cognition, 5(4), 415-425.

Hagyard, J. D., Brimmell, J., Edwards, E. J., \& Vaughan, R. S. (2020). Inhibitory control across athletic expertise and its relationship with sport performance. Journal of Sport and Exercise Psychology. Advanced Online Publication. https://doi.org/10.1123/jsep.20200043

Irvine, M. A., Worbe, Y., Bolton, S., Harrison, N. A., Bullmore, E. T., \& Voon, V. (2013). Impaired decisional impulsivity in pathological videogamers. PLoS One, 8(10). doi:10.1371/journal.pone.0075914 
Ishihara, T., \& Mizuno, M. (2018). Effects of tennis play on executive function in 6-11-year-old children: a 12-month longitudinal study. European Journal of Sport Science, 18(5), 741752.

Jacobson, J., \& Matthaeus, L. (2014). Athletics and executive functioning: How athletic participation and sport type correlate with cognitive performance. Psychology of Sport and Exercise, 15(5), 521-527.

Kagan, J. (1966). Reflection-impulsivity: The generality and dynamics of conceptual tempo. Journal of Abnormal Psychology, 71(1), 17.

Krenn, B., Finkenzeller, T., Würth, S., \& Amesberger, G. (2018). Sport type determines differences in executive functions in elite athletes. Psychology of Sport and Exercise, 38, 72-79.

Martin, K., Staiano, W., Menaspà, P., Hennessey, T., Marcora, S., Keegan, R., ... \& Rattray, B. (2016). Superior inhibitory control and resistance to mental fatigue in professional road cyclists. PloS One, 11(7), e0159907.

Miu, A. C., Heilman, R. M., \& Houser, D. (2008). Anxiety impairs decision-making: psychophysiological evidence from an Iowa Gambling Task. Biological Psychology, 77(3), 353-358.

Morgan, M. J., Impallomeni, L. C., Pirona, A., \& Rogers, R. D. (2006). Elevated impulsivity and impaired decision-making in abstinent Ecstasy (MDMA) users compared to polydrug and drug-naive controls. Neuropsychopharmacology, 31(7), 1562.

Nigg, C. R., Fuchs, R., Gerber, M., Jekauc, D., Koch, T., Krell-Roesch, J., ... \& Sattler, M. C. (2020). Assessing physical activity through questionnaires-A consensus of best practices and future directions. Psychology of Sport and Exercise, 101715.

Singer, R. N. (2000). Performance and human factors: Considerations about cognition and attention for self-paced and externally-paced events. Ergonomics, 43(10), 1661-1680. 
Spindler, D. J., Allen, M. S., Vella, S. A., \& Swann, S. (2017). Manipulating implicit beliefs about decision-making ability affects decision-making performance under submaximal physiological load. Sport, Exercise, and Performance Psychology, 6(2), 179-187.

Stanislaw, H., \& Todorov, N. (1999). Calculation of signal detection theory measures. Behavior Research Methods, Instruments, \& Computers, 31, 137-149.

Swann, C., Moran, A., \& Piggott, D. (2016). Defining elite athletes: Issues in the study of expert performance in sport psychology. Psychology of Sport and Exercise, 16(1), 3-14.

Tabachnick, B.G., \& Fidell, L.S. (2007). Using multivariate statistics. Boston: Allyn and Bacon. Tomporowski, P.D., Davis, C.L., Miller, P.H., \& Naglieri, J.A., (2008). Exercise and children's intelligence, cognition, and academic achievement. Educational Psychology Review, 20, $111-131$.

Vaughan, R., Laborde, S., McConville, C. (2018). The effect of athletic expertise and trait emotional intelligence on decision-making. European Journal of Sport Science, 19(2), $225-233$.

Verburgh, L., Scherder, E. J. A., van Lange, P. A., Oosterlaan, J. (2014). Executive functioning in highly talented soccer players. PLoS ONE 9(3), e91254. doi:10.1371/journal.pone.0091254

Vestberg, T., Gustafson, R., Maurex, L., Ingvar, M., \& Petrovic, P. (2012). Executive functions predict the success of top-soccer players. PLOS ONE, 7(4), e34731. doi:10.1371/journal.pone.0034731

Vestberg, T., Reinebo, G., Maurex, L., Ingvar, M., Petrovic, P., \& Ardigò, L. P. (2017). Core executive functions are associated with success in young elite soccer players. PLoS ONE, 12(2), e0170845. doi:10.1371/journal.pone.0170845 
Voss, M. W., Kramer, A. F., Basak, C., Prakash, R. S., \& Roberts, B. (2010). Are expert athletes 'expert' in the cognitive laboratory? A meta-analytic review of cognition and sports expertise. Applied Cognitive Psychology, 24, 812-826.

Walsh, V. (2014). Is sport the brain's biggest challenge? Current Biology, 24(18), R859-R860.

Wang, C. H., Chang, C. C., Liang, Y. M., Shih, C. M., Chiu, W. S., Tseng, P., ... \& Juan, C. H. (2013). Open vs. closed skill sports and the modulation of inhibitory control, PLOS ONE, 8(2), e55773. doi:10.1371/journal.pone.0055773

West, B. T. (2009). Analyzing longitudinal data with the linear mixed models procedure in SPSS. Evaluation \& the Health Professions, 32(3), 207-228.

Williams, L. R. T., Anshel, M. H., \& Quek, J. J. (1997). Cognitive style in adolescent competitive athletes as a function of culture and gender. Journal of Sport Behavior, $20(2), 232$.

Williams, A. M., \& Ericsson, K. A. (2005). Perceptual-cognitive expertise in sport: Some considerations when applying the expert performance approach. Human Movement Science, 24(3), 283-307.

Williams, A.M., Ford, P. R., Eccles, D. W., \& Ward, P. (2011). Perceptual-cognitive expertise in sport and its acquisition: Implications for applied cognitive psychology. Applied Cognitive Psychology, 25, 432-442.

Williams, A. M., \& Jackson, R. C. (2019). Anticipation in sport: Fifty years on, what have we learned and what research still needs to be undertaken? Psychology of Sport and Exercise, 42, 16-24. 
Figure 1. Plots for Linear Mixed Model of IST Effectiveness at Time 1 and Time 2 across Athletic Expertise.

IST Effectiveness at Time 1 and Time 2 across Athletic Expertise

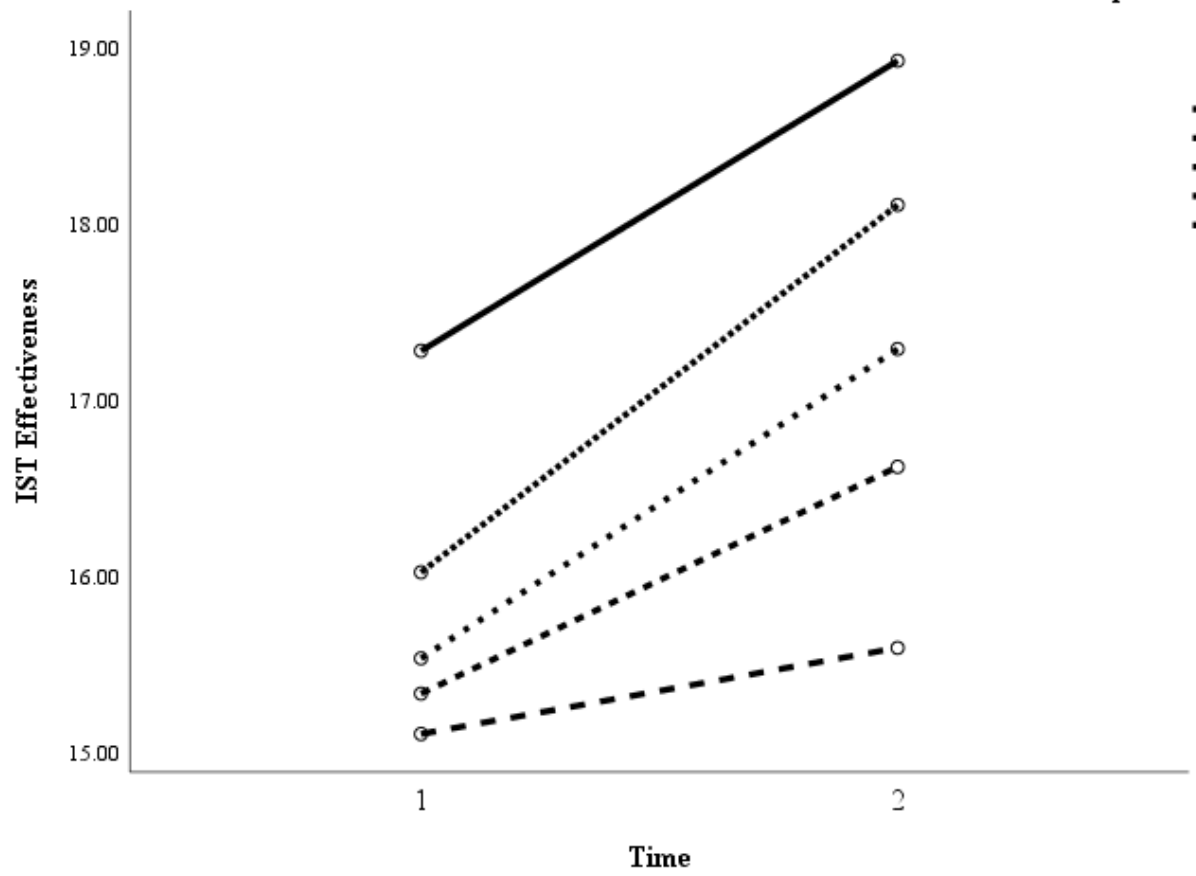

Athletic Expertise

- - Non-Athlete - Novice - Amateur ..... Elite - Super elite

Time 
Figure 2. Plots for Linear Mixed Model of IST Efficiency at Time 1 and Time 2 across Athletic Expertise.

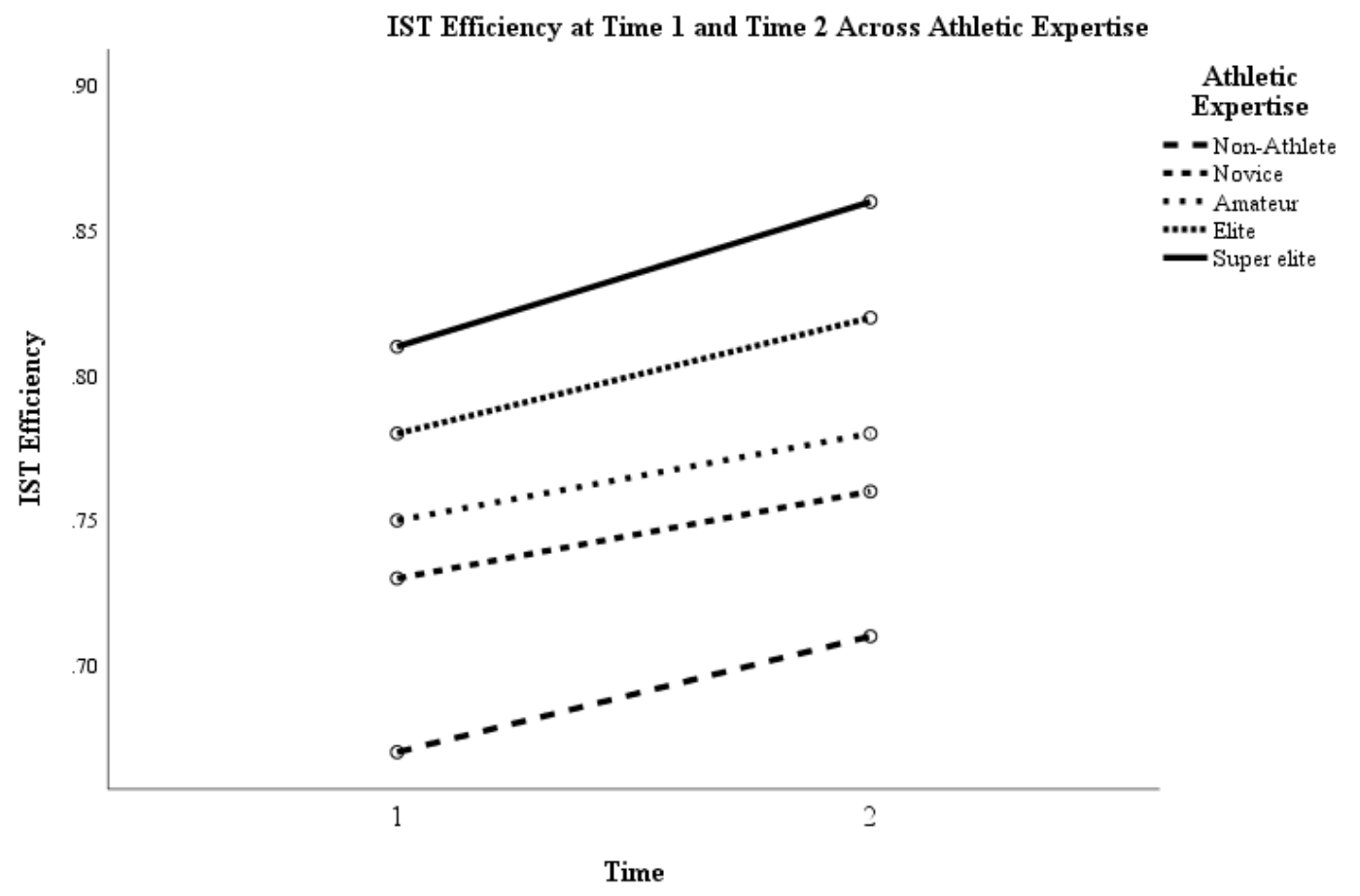


Table 1. Mean Effectiveness and Efficiency ( \pm SD) on the Information Sampling Task across Sport Type in Study 1 and Study 2

\begin{tabular}{|c|c|c|c|c|c|c|c|c|c|}
\hline \multicolumn{10}{|c|}{$M(S D)$} \\
\hline & Variable & Total & $\begin{array}{l}\text { Self- } \\
\text { Paced }\end{array}$ & $\begin{array}{c}\text { Externally- } \\
\text { Paced }\end{array}$ & $\begin{array}{l}\text { Non- } \\
\text { Athletes }\end{array}$ & Novice & Amateur & Elite & $\begin{array}{l}\text { Super } \\
\text { Elite }\end{array}$ \\
\hline \multicolumn{10}{|c|}{ Study 1} \\
\hline \multirow{2}{*}{$\begin{array}{l}(N= \\
108)\end{array}$} & $\begin{array}{l}\text { Effectiveness } \\
\left(d^{\prime}\right)\end{array}$ & $\begin{array}{l}15.12 \\
(1.36)\end{array}$ & $\begin{array}{l}16.01 \\
(1.48)\end{array}$ & $\begin{array}{l}16.29 \\
(1.31)\end{array}$ & $\begin{array}{l}13.70 \\
(1.47)\end{array}$ & $\begin{array}{l}14.48 \\
(1.41)\end{array}$ & $\begin{array}{l}15.70 \\
(1.10)\end{array}$ & $\begin{array}{l}16.22 \\
(1.21)\end{array}$ & $\begin{array}{l}17.65 \\
(1.02)\end{array}$ \\
\hline & Efficiency & $\begin{array}{l}.78 \\
(.10)\end{array}$ & $\begin{array}{l}.79 \\
(.09)\end{array}$ & $.80(.08)$ & $\begin{array}{l}.72 \\
(.09)\end{array}$ & .75 & & $\begin{array}{l}.81 \\
(.06)\end{array}$ & $\begin{array}{l}.84 \\
(.06)\end{array}$ \\
\hline \multicolumn{10}{|c|}{ Study 2} \\
\hline \multirow{2}{*}{$\begin{array}{l}\text { Time } 1 \\
(N= \\
106)\end{array}$} & $\begin{array}{l}\text { Effectiveness } \\
\left(d^{\prime}\right)\end{array}$ & $\begin{array}{l}15.69 \\
(1.96)\end{array}$ & $\begin{array}{l}15.58 \\
(1.72)\end{array}$ & $\begin{array}{l}15.91 \\
(1.78)\end{array}$ & 15.10 & $\underbrace{15.33}_{(1.87)}$ & $\begin{array}{l}15.53 \\
(1.54)\end{array}$ & $\begin{array}{l}16.02 \\
(1.59)\end{array}$ & $\begin{array}{l}17.28 \\
(.89)\end{array}$ \\
\hline & Efficiency & $\begin{array}{l}.73 \\
(.11)\end{array}$ & $\begin{array}{l}.74 \\
(.10)\end{array}$ & & $\begin{array}{l}.67 \\
(.10)\end{array}$ & $\begin{array}{l}.73 \\
(.08)\end{array}$ & $.75(.07)$ & $\begin{array}{l}.78 \\
(.06)\end{array}$ & $\begin{array}{l}.81 \\
(.06)\end{array}$ \\
\hline \multirow{2}{*}{$\begin{array}{l}\text { Time } 2 \\
(N= \\
64)\end{array}$} & $\begin{array}{l}\text { Effectiveness } \\
\left(d^{\prime}\right)\end{array}$ & $\begin{array}{l}16.74 \\
(1.41)\end{array}$ & 16.58 & $\begin{array}{l}17.05 \\
(1.31)\end{array}$ & $\begin{array}{l}15.59 \\
(1.43)\end{array}$ & $\begin{array}{l}16.62 \\
(1.33)\end{array}$ & $\begin{array}{l}17.29 \\
(.98)\end{array}$ & $\begin{array}{l}18.11 \\
(.91)\end{array}$ & $\begin{array}{l}18.93 \\
(.48)\end{array}$ \\
\hline & Efficien & $\begin{array}{l}82 \\
(.10)\end{array}$ & $\begin{array}{l}.81 \\
(.11)\end{array}$ & $.82(.10)$ & $\begin{array}{l}.72 \\
(.09)\end{array}$ & $\begin{array}{l}.76 \\
(.09)\end{array}$ & $.78(.09)$ & $\begin{array}{l}.82 \\
(.07)\end{array}$ & $\begin{array}{l}.86 \\
(.06)\end{array}$ \\
\hline
\end{tabular}


Table 2. Between-Subjects Analysis of Covariance for the Association between Athletic Expertise and Performance on the Information Sampling Task.

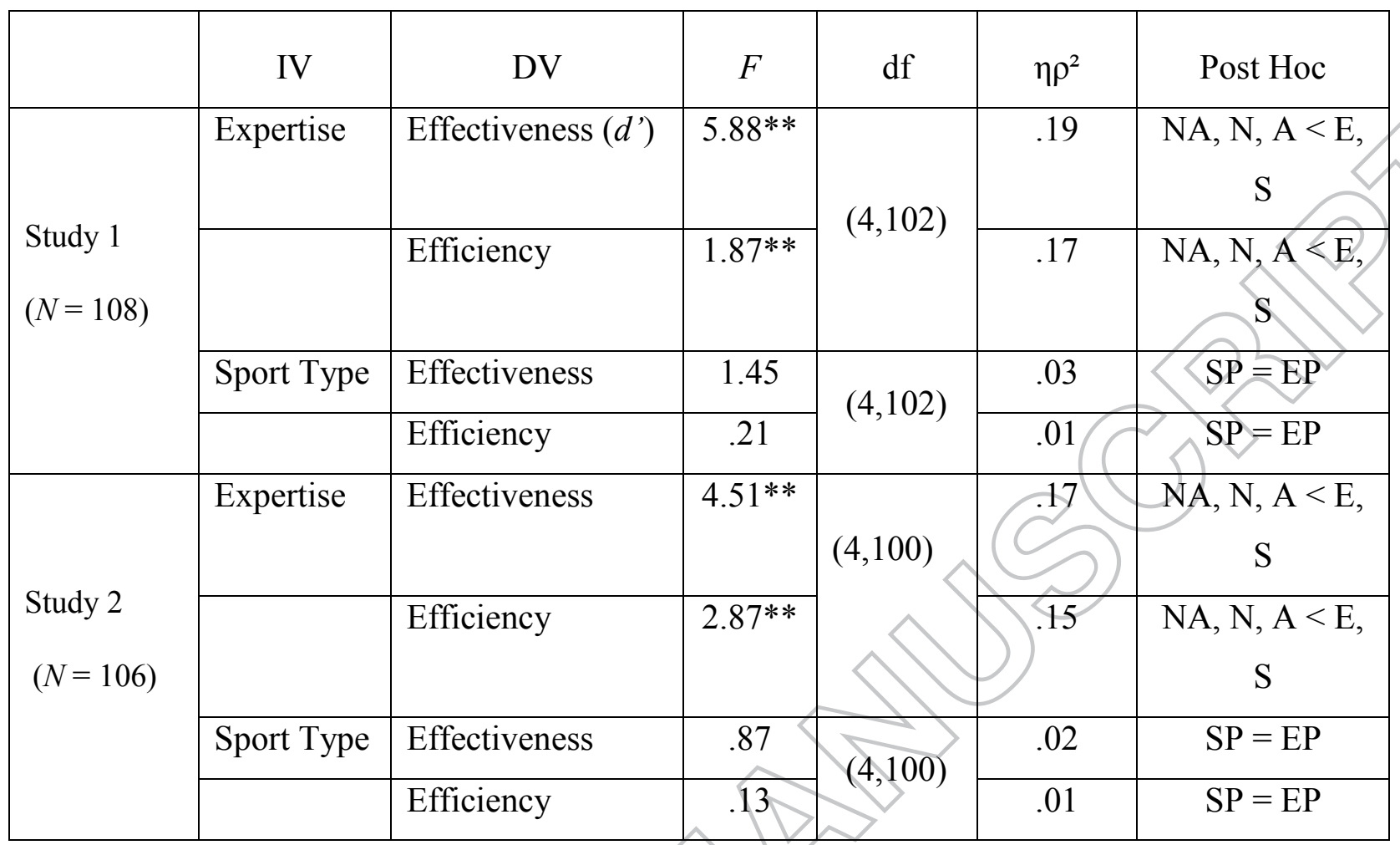

Note. Covariate Physical Activity insignificant across all models $(p>.05)$. IV $=$ Independent Variables, DV =

Dependent Variables. $\mathrm{SP}=$ Self-Paced Athlete, $\mathrm{EP}=$ External-Paced Athlete, $\mathrm{NA}=$ Non-Athlete, $\mathrm{N}=$ Novice, $\mathrm{A}=$ Amateur, $\mathrm{E}=$ Elite, $\mathrm{S}=$ Super-Elite. IST = Information Sampling Task; $p<.01 * *, p<.05^{*}$

Table 3. Demographic Characteristics of Study 2 Participants at Time 1 and Time 2.

\begin{tabular}{|c|c|c|c|c|c|c|c|c|}
\hline & & Athlete & at $\mathrm{TI}(n=$ & $\begin{array}{l}\text { Athlet } \\
(n=5\end{array}$ & at T2 & $\begin{array}{l}\text { Non- } \\
\text { athletes } \\
\text { at T1 } \\
(n=37)\end{array}$ & $\begin{array}{l}\text { Non- } \\
\text { athletes } \\
\text { at T2 } \\
(n=14)\end{array}$ & $\begin{array}{l}\text { Total } \\
(\mathrm{N}= \\
106)\end{array}$ \\
\hline & & $\begin{array}{c}\text { Self- } \\
\text { Paced } \\
(n= \\
43)\end{array}$ & $\begin{array}{l}\text { Externally- } \\
\text { Paced ( } n= \\
26)\end{array}$ & $\begin{array}{l}\text { Self- } \\
\text { Paced } \\
(n= \\
30)\end{array}$ & $\begin{array}{l}\text { Externally- } \\
\text { Paced }(n= \\
20)\end{array}$ & & & \\
\hline $\begin{array}{l}\text { Age } \\
(18-37\end{array}$ & $M(S D)$ & $\begin{array}{l}22.72 \\
(8.35)\end{array}$ & $\begin{array}{l}20.92 \\
(2.95)\end{array}$ & $\begin{array}{l}22.13 \\
(7.25)\end{array}$ & $\begin{array}{l}21.24 \\
(3.05)\end{array}$ & $\begin{array}{l}19.97 \\
(2.36)\end{array}$ & $\begin{array}{l}20.21 \\
(2.67)\end{array}$ & $\begin{array}{l}21.32 \\
(5.77)\end{array}$ \\
\hline
\end{tabular}




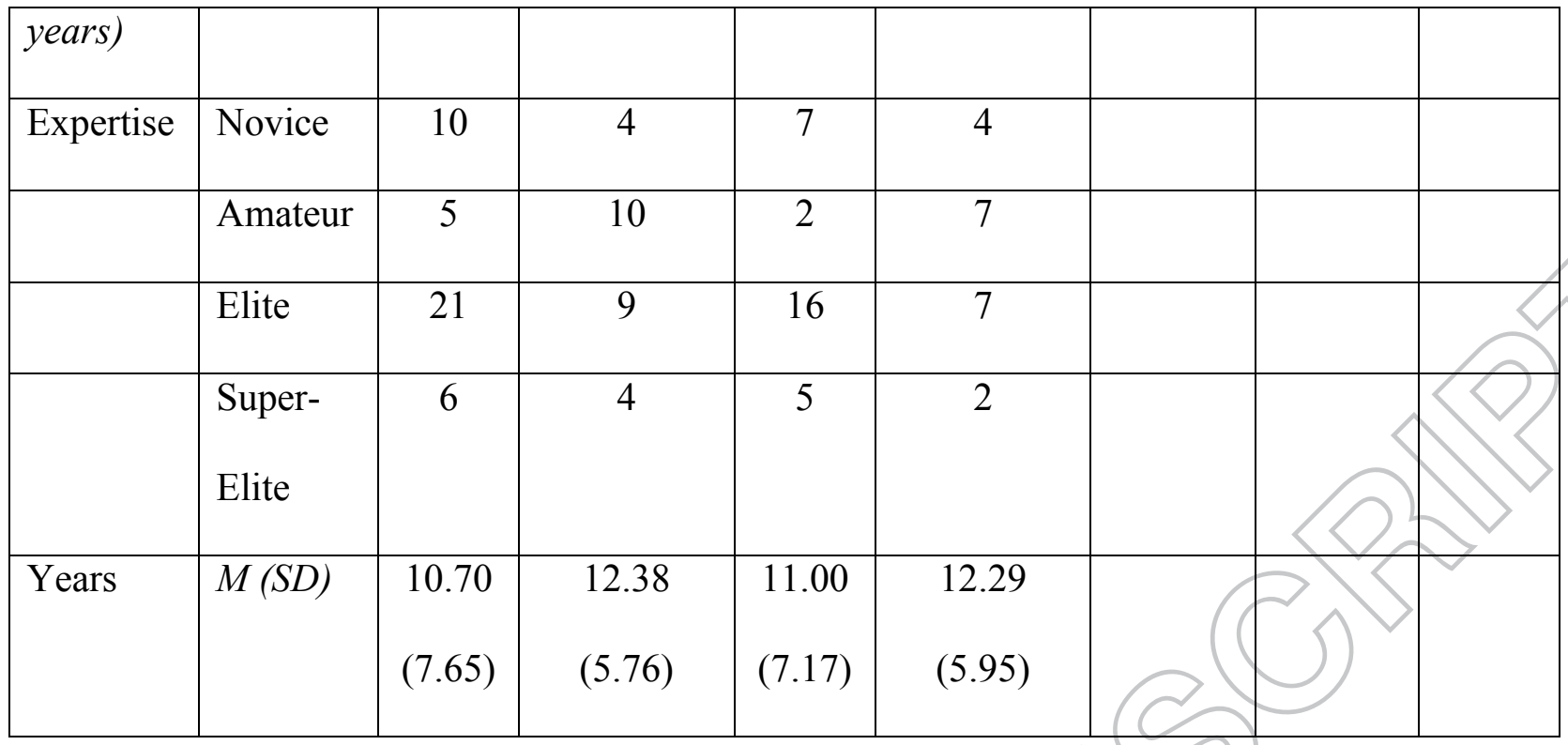

Note: Years $=$ Mean Length of Time Participating in Sport.

Table 4. Summary of Linear Mixed Models Results.

\begin{tabular}{|l|c|c|c|c|c|c|}
\hline \multicolumn{1}{|c|}{ Variable } & \multicolumn{2}{|c|}{$\begin{array}{c}\text { Descriptives of Model } \\
\text { Summary }\end{array}$} & \multicolumn{2}{|c|}{ Test of Fixed Effect } & \multicolumn{2}{c|}{ Covariance } \\
& Time 1 & Time 2 & & $F^{(4,59)}$ & $\beta(\mathrm{CI})$ & Wald Z \\
\hline Effectiveness $\left(d^{\prime}\right)$ & 15.69 & 16.64 & $5.16^{* *}$ & $10.36^{* *}$ & $1.98(1.35-2.34)$ & $5.61^{* *}$ \\
\hline Efficiency & .73 & .82 & $2.89^{* *}$ & $5.74^{* *}$ & $1.18(.92-1.80)$ & $5.65^{* *}$ \\
\hline
\end{tabular}

Note. $\mathrm{CI}=95 \%$ Confidence Intervals. IST $=$ Information Sampling Task. $N=64 . p<.05^{*}, p<.01^{* *}$ 